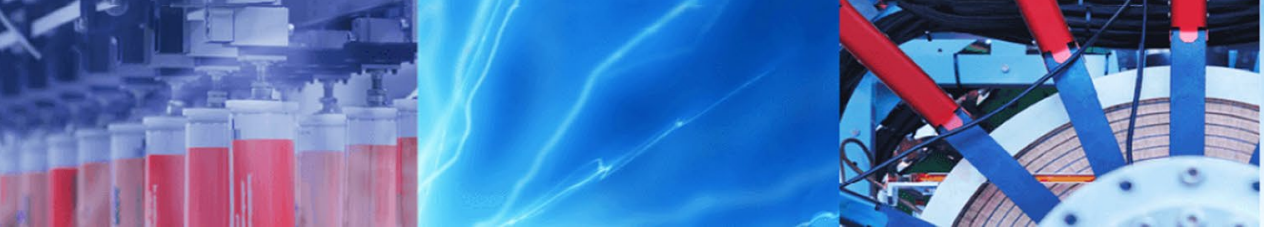

Research Article

\title{
Molecular structure, electronic properties and drug-likeness of xylazine by quantum methods and qsar analysis
}

\author{
J. Deva Anban ${ }^{1,4} \cdot$ C. James ${ }^{2,4} \cdot$ J. Sharmi Kumar ${ }^{3} \cdot$ Sayantan Pradhan $^{5}$ D
}

Received: 1 April 2020 / Accepted: 3 September 2020 / Published online: 12 September 2020

(c) Springer Nature Switzerland AG 2020

\begin{abstract}
Xylazine is an adrenergic alpha-2 agonist used as a sedative, analgesic and centrally acting muscle relaxant in veterinary medicine. In this study, the anaesthetic compound Xylazine was optimized in the electronic ground state using Density Functional Theory at B3LYP/6-311 + G (d, p) level. This study aims at revealing the various electro physical and chemical properties of Xylazine. This study will be useful for future research on the title compound. The stabilization energies and the electronic transitions were achieved with the aid of Natural Bond Orbital (NBO) analysis. The vibrational pattern of the molecule was characterized by FT-IR and FT-Raman spectra using Scaled Quantum Mechanical Force Field calculations. The presence of strong hydrogen bonding interactions was evidently revealed by the shifting of wavenumbers. NBO analysis reveals the stability of the molecule. Further, the strength of association between adrenergic receptor and Xylazine was predicted using a computer-based analysis of molecular modeling interaction techniques. A detailed molecular picture of this anesthetic compound and its interactions were obtained by modeling analysis, NBO analysis, IR, Raman and UV-Vis spectroscopy.
\end{abstract}

Keywords DFT · NBO $\cdot$ NCA · Docking $\cdot$ QSAR $\cdot$ Drug-likeness

\section{Introduction}

Veterinary anaesthesia is one of the most promising branches in medical science because of its prominence in certain diagnostic processes, surgical and medical intervention. Insensitivity to pain is induced in animals using anaesthetic drugs during surgical procedures and other medical interventions. In veterinary anaesthesia, the dissimilarities in anatomy and metabolism of species reduce the feasibility of anaesthetics and bring down its scope. Veterinarians are thus left to explore different possibilities and its aspects. Xylazine is a drug used in veterinary practice for its effective sedative, analgesic, myrolexant and anaesthetic properties [1]. It is easily accessible for its smooth diagnostic and therapeutic process on uncooperative patients. It has four well-known polymorphic conformations ( $A, M, Z$ and $X)$ and a few pseudo polymorphs, from which monohydrate is the most stable one [2]. Xylazine instigate extended analgesia with long-lasting duration of action when injected into the subarachnoid space. This analgesic aftermath is intervened by $a 2$ adrenergic receptors spotted in the dorsal horn of the spinal cord [3, 4]. Adrenergic a 2 receptors are entailed in several physiological and pathophysiological phenomena [5]. Even

Electronic supplementary material The online version of this article (https://doi.org/10.1007/s42452-020-03493-5) contains supplementary material, which is available to authorized users.

$\checkmark$ Sayantan Pradhan, sayan23us@gmail.com | 'Department of Physics, Pioneer Kumaraswamy College, Nagercoil 629003, Tamil Nadu, India. ${ }^{2}$ Department of Physics and Research Centre, Scott Christian College (Autonomous), Nagercoil 629003, Tamil Nadu, India. ${ }^{3}$ Department of Physics, Women's Christian College, Chennai 600 006, India. ${ }^{4}$ Manonmaniam Sundaranar University, Tirunelveli, India. ${ }^{5}$ Department of Chemistry, Jadavpur University, Kolkata, India. 
though Xylazine has an ample margin of safety, it induces dose-dependent side effects like a decline in gastrointestinal motility and cardiorespiratory function. It also triggers slight hypotension and respiratory depression [6]. Veterinary drugs on animals especially those which are bound for human consumption necessitates careful pharmacodynamics and pharmacokinetic studies.

Quantum chemistry techniques play an important role in obtaining molecular geometries and predicting various properties [7]. This study aims at revealing the various electro physical and chemical properties of Xylazine. In this work, Density Functional Theory (DFT) is used to attain detailed geometrical and physical properties. Frontier molecular orbitals (FMO) and Global reactivity descriptors are calculated to speculate the reactivity of the molecule. The natural bond orbital analysis has been carried out to review the stability of the molecule emerging from hyper conjugative interaction and charge delocalization. Molecular modeling is a useful tool for the characterization of structure-function relationships, which play dominant roles in the binding processes. Quantitative Structure-Activity Relationship (QSAR) helps to understand the fundamental activity and phenomena in medicinal chemistry and drug design.

\subsection{Material and computation}

Xylazine (spectroscopic grade) was purchased from Sigma-Aldrich Chemicals, USA. Density Functional Theory (DFT) calculation was performed using GAUSSIAN 09 program [8] and the molecular geometries was accomplished using Becke-3-Lee-Yang-Parr (B3LYP) [9, 10], 6-311 + G (d, p) basis set without any restriction. Natural bond orbital (NBO) analysis using NBO 3.1 [11] was carried out to view the charge transfer between atoms for intra and intermolecular hydrogen bonding present in the molecule.

The FT-IR spectrum was recorded using the standard $\mathrm{KBr}$ pellet technique with a Jasco FTIR-6300 instrument in the spectral range $4000-450 \mathrm{~cm}^{-1}$. The FT-Raman spectrum was recorded using Brucker: RFS 100/S instrument with a $1064 \mathrm{~nm} \mathrm{Nd:YAG} \mathrm{laser} \mathrm{source} \mathrm{of} 150 \mathrm{~mW}$ power in the spectral range $4000-50 \mathrm{~cm}^{-1}$. Normal coordinate analysis (NCA) was performed to obtain theoretical support for the assignment of vibrational frequencies using MOLVIB program version $7.0[12,13]$ and further refined by Scaled Quantum Mechanical Force Field calculations (SQMFF). Molecular docking simulation was executed on AutoDock Vina software [14]. The 3D crystal structure of bovine (Bos taurus) adrenergic receptor was obtained from Protein Data Bank (PDBID:3PVW). Auto Dock Tools (ADT) graphical user interface was used to compute Kollman charges and to add polar hydrogen. The ideal algorithm, Lamarckin Genetic Algorithm (LGA) available in Auto Dock Vina was employed for docking [15]. Active site of the protein is defined in a manner that its incorporated residues of the active site are within the grid dimensions of $30 \times 30 \times 30 \AA$. The 3D structures of Xylazine and its structural analogues are retrieved from PubChem database. Xylazine and its structural analogues are docked into the active site of adrenergic receptor using standard Autodock vina protocol and after docking the docking scores are documented.

\section{Results and discussion}

\subsection{Molecular structure analysis}

The two-dimensional structure and the optimized molecular structure of Xylazine are shown in Fig. 1a, b respectively. Selective geometrical parameters pertinent to this study are given in Table 1. The experimental bond length and bond angle values are obtained from the work of M.V.Veidis et al. [16]. The $\mathrm{C}-\mathrm{C}$ bond lengths in the phenyl ring remains in the expected region 1.391 Á-1.404 Á. The attachment of methyl groups in the phenyl ring decreases the bond angles of $\mathrm{C}_{1-} \mathrm{C}_{6-} \mathrm{C}_{5}\left(117.83^{\circ}\right)$ and $\mathrm{C}_{3-} \mathrm{C}_{4-} \mathrm{C}_{5}$ $\left(117.75^{\circ}\right)$. The nitrogen atom $\mathrm{N}_{18}$ attached to the benzene ring reduces the $\mathrm{C}_{5}-\mathrm{N}_{18}$ bond length (1.436 $\AA$ ) from its

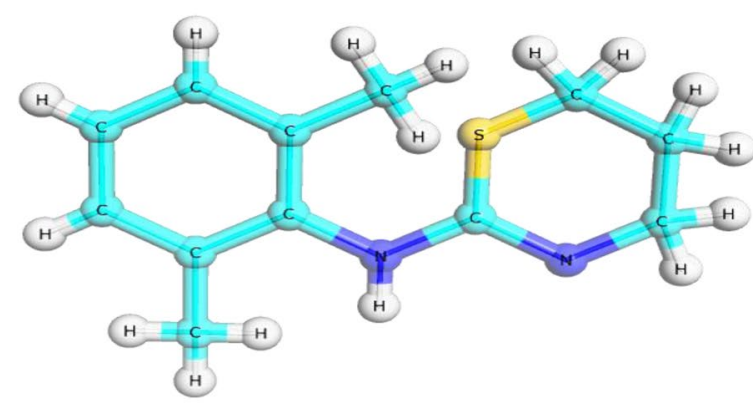

(a)

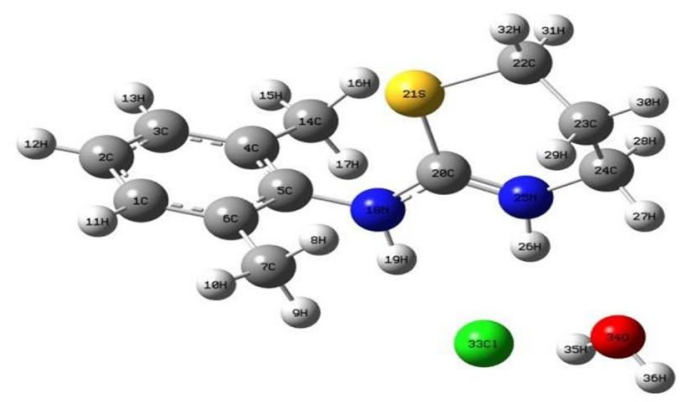

(b)

Fig.1 a 2-Dimesional structure of Xylazine, b Optimized molecular structure of Xylazine 
Table 1 Comparison between experimental values and theoretically optimized geometrical parameters of Xylazine

\begin{tabular}{lcc}
\hline Parameters & Experimental & Calculated \\
\hline Bond length $(\AA)$ & & \\
$\mathrm{C}_{1}-\mathrm{C}_{2}$ & 1.386 & 1.391 \\
$\mathrm{C}_{2}-\mathrm{C}_{3}$ & 1.383 & 1.391 \\
$\mathrm{C}_{3}-\mathrm{C}_{4}$ & 1.400 & 1.396 \\
$\mathrm{C}_{4}-\mathrm{C}_{5}$ & 1.395 & 1.404 \\
$\mathrm{C}_{5}-\mathrm{C}_{6}$ & 1.403 & 1.404 \\
$\mathrm{C}_{6}-\mathrm{C}_{1}$ & 1.391 & 1.397 \\
$\mathrm{C}_{5}-\mathrm{N}_{18}$ & 1.442 & 1.436 \\
$\mathrm{~N}_{18}-\mathrm{C}_{20}$ & 1.336 & 1.322 \\
$\mathrm{C}_{20}-\mathrm{N}_{25}$ & 1.311 & 1.328 \\
$\mathrm{~N}_{18}-\mathrm{H}_{19}$ & 0.870 & 1.071 \\
$\mathrm{C}_{20}-\mathrm{S}_{21}$ & 1.740 & 1.774 \\
Bond angle $\left.^{\circ}\right)$ & & \\
$\mathrm{C}_{1}-\mathrm{C}_{2}-\mathrm{C}_{3}$ & 120.93 & 120.22 \\
$\mathrm{C}_{2}-\mathrm{C}_{3}-\mathrm{C}_{4}$ & 121.14 & 120.91 \\
$\mathrm{C}_{4}-\mathrm{C}_{5}-\mathrm{C}_{6}$ & 122.60 & 122.36 \\
$\mathrm{C}_{1}-\mathrm{C}_{6}-\mathrm{C}_{5}$ & 118.55 & 117.83 \\
$\mathrm{C}_{3}-\mathrm{C}_{4}-\mathrm{C}_{5}$ & 117.01 & 117.75 \\
$\mathrm{C}_{6}-\mathrm{C}_{1}-\mathrm{C}_{2}$ & 119.74 & 120.84 \\
$\mathrm{C}_{22}-\mathrm{S}_{21}-\mathrm{C}_{20}$ & 102.41 & 102.83 \\
\hline & &
\end{tabular}

standard value. The shortening of $\mathrm{N}_{18}-\mathrm{C}_{20}(1.322 \AA)$ and

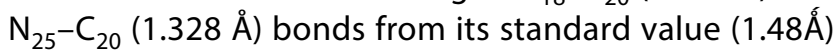
reveals the typical double bond character as an after-effect of resonance interaction [17]. The structure is stabilized by an extensive network of $\mathrm{N}_{18-} \mathrm{H}_{19} \cdots \mathrm{Cl}_{33}, \mathrm{~N}_{25} \mathrm{H}_{26} \cdots \mathrm{O}_{34}$ and $\mathrm{O}_{34}-\mathrm{H}_{35} \cdots \mathrm{Cl}_{33}$ hydrogen bonds. The six-membered ring forms a half-chair conformation and the bond distances differ significantly from each other due to the variation of electro negativities of the atoms. The delocalization of lone pair $S_{21}$ towards $C_{20}$ atom considerably reduces the $C_{20}-S_{21}$ bond length (1.774 $\AA$ ). The lone pair of $\mathrm{N}_{25}$ is also delocalized towards both of its $\mathrm{sp}_{2}$ neighbour carbons $\mathrm{C}_{20}$ and $\mathrm{C}_{24}$. The bond angle $\mathrm{C}_{22-} \mathrm{S}_{21-} \mathrm{C}_{20}\left(102.83^{\circ}\right)$ decreases due to the smaller electronegativity of the central sulphur atom.

\subsection{NBO analysis}

NBO analysis provide the feasible 'natural Lewis structure' picture of $\varphi$, because orbital features are mathematically chosen to incorporate the highest possible percentage of the electron density [18]. As obvious from Table 2, the electron density of the conjugated $\pi$ bonds and $\pi^{*}$ bonds are $\sim 1.668$ e and $\sim 0.338$ e respectively, which reveals strong $\pi$ electron delocalization within the benzene ring leading to a maximum stabilization energy of $\sim 23.70 \mathrm{kcal} /$ mol. The electron densities of $\sigma$ and $\sigma^{*}$ bonds of the phenyl ring are $\sim 1.973$ e and $\sim 0.024$ e respectively, which shows weak charge delocalization leading to a maximum stabilization energy of $\sim 5.51 \mathrm{kcal} / \mathrm{mol}$. The charge transfer from the methyl group to the phenyl ring are disclosed from the interaction of the methyl orbitals $\left[\sigma\left(\mathrm{C}_{7-} \mathrm{H}_{8}\right)\right.$ and $\left.\sigma\left(\mathrm{C}_{7-} \mathrm{H}_{9}\right)\right]$ with the germinal $\pi^{*}\left(\mathrm{C}_{1-} \mathrm{C}_{6}\right)$ orbital and $\left[\sigma\left(\mathrm{C}_{14}-\mathrm{H}_{15}\right)\right.$ and $\sigma$ $\left.\left(\mathrm{C}_{14}-\mathrm{H}_{16}\right)\right]$ with the germinal $\pi^{*}\left(\mathrm{C}_{4}-\mathrm{C}_{5}\right)$ orbital. The hyperconjugation and electron density transfer from lone pair (LP) of the $\mathrm{Y}$ atom to the $\mathrm{X}-\mathrm{H}$ antibonding orbital in the $\mathrm{X}-\mathrm{H} \cdots \mathrm{Y}$ system reveals the importance of stabilization, which has been reported earlier [19-21]. NBO analysis shows the existence of hyperconjugative interaction LP $\left(\mathrm{O}_{34}\right) \rightarrow \sigma^{*}\left(\mathrm{~N}_{25}-\mathrm{H}_{26}\right)$ with energy $25.02 \mathrm{kcal} / \mathrm{mol}$. This interaction contributes a strong stabilization to the system of the title compound and strengthens the $\mathrm{N}_{25} \mathrm{H}_{26} \cdots \mathrm{O}_{34}$ hydrogen bond. The electron donation from $\mathrm{LP}(4)-\mathrm{Cl}_{33}$ to the antibonding acceptor $\sigma^{*}\left(\mathrm{~N}_{18}-\mathrm{H}_{19}\right)$ promotes a stabilization energy of $7.10 \mathrm{kcal} / \mathrm{mol}$, which denotes that the chloride anion is large and its electron density is overlapping with the organic cation. This exhibits the intramolecular $\mathrm{N}_{18}-\mathrm{H}_{19} \cdots \mathrm{Cl}_{33}$ interaction. The $\mathrm{LP}$ of $\mathrm{Cl}_{33}$ donates its electron to the $\sigma$ type antibonding orbital for $\mathrm{O}_{34}-\mathrm{H}_{35}$ and the stabilization energy of $\mathrm{O}_{34-} \mathrm{H}_{35} \cdots \mathrm{Cl}_{33}$ bonding is $3.49 \mathrm{kcal} / \mathrm{mol}$. These $\mathrm{N}-\mathrm{H} \cdots \mathrm{O}, \mathrm{N}-\mathrm{H} \cdots \mathrm{Cl}$ and $\mathrm{O}-\mathrm{H} \cdots \mathrm{Cl}$ hydrogen bonding interactions significantly influences the crystal packing of this molecule.

\subsection{Molecular electrostatic potential surface analysis}

The electron density mapped with Molecular Electrostatic Potential (MEP) surface represents the chemically active sites of a molecule. Electrostatic potential plays a vital part in perceiving the molecular reactivity, electrophilic reactions, and substituent effects $[22,23]$. The electrostatic potential $V(r)$ at any point in space around the molecule by charge distribution is given by

$V(r)=\in \frac{Z_{A}}{R_{A}-r} \int \frac{\rho\left(r^{\prime}\right) d r}{\left|r^{\prime}-r\right|}$

where the summation extends over all the nuclei $A$ in the molecule neglecting polarization and reorganization effects. $Z_{A}$ is the charge of the nucleus $A$ located at $R_{A}$ and $\rho\left(r^{\prime}\right)$ is the electron density function of the molecule. Figure 2 displays the plot of the total electron density mapped with MEP surface of the Xylazine molecule. The low potential region, red (negative MEP) is characterized by very large quantity of electrons. This is the region of electrophilic attack. The high potential region, blue (positive MEP) is characterized by relative shortfall of electrons. This area is the region of nucleophillic attack. It is found that the carbon atoms in benzene ring has negative charges and hence belong to the negative electrostatic 
Table 2 Second order perturbation theory analysis of Fock matrix in NBO basis

\begin{tabular}{|c|c|c|c|c|c|c|}
\hline Donar (i) & ED (i) (e) & Energy & Acceptor (j) & $E D(j)(e)$ & Energy & $\begin{array}{l}\mathrm{E}(2)^{\mathrm{a}} \\
(\mathrm{kcal} \\
\left.\mathrm{mol}^{-1}\right)\end{array}$ \\
\hline$\sigma C_{1}-C_{2}$ & 1.97683 & -0.68816 & $\sigma^{*} C_{1}-C_{6}$ & 0.02154 & 0.58753 & 3.48 \\
\hline$\sigma C_{1}-C_{6}$ & 1.97237 & -0.69206 & $\sigma^{*} C_{1}-C_{2}$ & 0.01760 & 0.58259 & 3.12 \\
\hline$\sigma C_{1}-C_{6}$ & 1.97237 & -0.69206 & $\sigma^{*} C_{5}-C_{6}$ & 0.03278 & 0.61608 & 3.36 \\
\hline$\sigma C_{1}-C_{6}$ & 1.97237 & -0.69206 & $\sigma^{*} C_{5}-N_{18}$ & 0.03458 & 0.36004 & 4.35 \\
\hline$\pi C_{1}-C_{6}$ & 1.63981 & -0.25027 & $\pi^{*} C_{2}-C_{3}$ & 0.32343 & 0.02850 & 23.70 \\
\hline$\pi C_{1}-C_{6}$ & 1.63981 & -0.25027 & $\pi^{*} C_{4}-C_{5}$ & 0.37628 & 0.02535 & 18.68 \\
\hline$\sigma \mathrm{C}_{7}-\mathrm{H}_{8}$ & 1.97343 & -0.54442 & $\pi^{*} C_{1}-C_{6}$ & 0.31589 & 0.03637 & 4.01 \\
\hline$\sigma \mathrm{C}_{7}-\mathrm{H}_{9}$ & 1.97663 & -0.53670 & $\pi^{*} C_{1}-C_{6}$ & 0.31589 & 0.03637 & 2.64 \\
\hline$\sigma C_{2}-C_{3}$ & 1.97579 & -0.69309 & $\sigma^{*} C_{3}-C_{4}$ & 0.02230 & 0.62091 & 3.37 \\
\hline$\sigma C_{2}-C_{3}$ & 1.97579 & -0.69309 & $\sigma^{*} C_{4}-C_{14}$ & 0.01748 & 0.43038 & 3.32 \\
\hline$\pi C_{2}-C_{3}$ & 1.67709 & -0.25689 & $\pi^{*} C_{1}-C_{6}$ & 0.31589 & 0.03637 & 17.06 \\
\hline$\pi C_{2}-C_{3}$ & 1.67709 & -0.25689 & $\pi^{*} C_{4}-C_{5}$ & 0.37628 & 0.02535 & 23.11 \\
\hline$\sigma \mathrm{C}_{14}-\mathrm{H}_{15}$ & 1.98166 & -0.55601 & $\pi^{*} C_{4}-C_{5}$ & 0.37628 & 0.02535 & 1.60 \\
\hline$\sigma \mathrm{C}_{14}-\mathrm{H}_{16}$ & 1.97351 & -0.55497 & $\pi^{*} C_{4}-C_{5}$ & 0.37628 & 0.02535 & 4.57 \\
\hline$\sigma C_{3}-C_{4}$ & 1.97091 & -0.68826 & $\sigma^{*} C_{2}-C_{3}$ & 0.01768 & 0.57826 & 3.53 \\
\hline$\sigma C_{3}-C_{4}$ & 1.97091 & -0.68826 & $\sigma^{*} C_{4}-C_{5}$ & 0.03242 & 0.58195 & 3.63 \\
\hline$\sigma C_{3}-C_{4}$ & 1.97091 & -0.68826 & $\sigma^{*} \mathrm{C}_{5}-\mathrm{N}_{18}$ & 0.03458 & 0.36004 & 5.39 \\
\hline$\sigma C_{4}-C_{5}$ & 1.97196 & -0.71757 & $\sigma^{*} C_{5}-C_{6}$ & 0.03278 & 0.61608 & 5.25 \\
\hline$\pi C_{4}-C_{5}$ & 1.68804 & -0.26775 & $\pi^{*} C_{1}-C_{6}$ & 0.31589 & 0.03637 & 22.60 \\
\hline$\pi C_{4}-C_{5}$ & 1.68804 & -0.26775 & $\pi^{*} C_{2}-C_{3}$ & 0.32343 & 0.02850 & 15.86 \\
\hline$\sigma C_{4}-C_{14}$ & 1.97921 & -0.62321 & $\sigma^{*} C_{5}-C_{6}$ & 0.03278 & 0.61608 & 3.43 \\
\hline$\sigma C_{5}-C_{6}$ & 1.97019 & -0.70712 & $\sigma^{*} C_{4}-C_{5}$ & 0.03242 & 0.58195 & 5.51 \\
\hline$\sigma C_{5}-C_{6}$ & 1.97019 & -0.70712 & $\sigma^{*} C_{4}-C_{14}$ & 0.01748 & 0.43038 & 2.92 \\
\hline$\sigma C_{5}-N_{18}$ & 1.97910 & -0.77561 & $\sigma^{*} C_{20}-N_{25}$ & 0.02906 & 0.48456 & 3.57 \\
\hline$\sigma C_{6}-C_{7}$ & 1.97846 & -0.61205 & $\sigma^{*} C_{4}-C_{5}$ & 0.03242 & 0.58195 & 3.70 \\
\hline$\sigma C_{7}-H_{10}$ & 1.98575 & -0.54319 & $\sigma^{*} C_{5}-C_{6}$ & 0.03278 & 0.61608 & 4.09 \\
\hline$\sigma \mathrm{C}_{14}-\mathrm{H}_{15}$ & 1.98166 & -0.55601 & $\sigma^{*} C_{4}-C_{5}$ & 0.03242 & 0.58195 & 3.30 \\
\hline$\sigma \mathrm{N}_{18}-\mathrm{H}_{19}$ & 1.97542 & -0.76490 & $\sigma^{*} C_{20}-S_{21}$ & 0.03379 & 0.18685 & 4.51 \\
\hline$\sigma N_{18}-C_{20}$ & 1.98394 & -0.90185 & $\sigma^{*} C_{24}-\mathrm{N}_{25}$ & 0.02130 & 0.27720 & 2.99 \\
\hline$\sigma C_{20}-S_{21}$ & 1.97701 & -0.73435 & $\sigma^{*} \mathrm{~N}_{18}-\mathrm{H}_{19}$ & 0.04012 & 0.78093 & 2.98 \\
\hline$\sigma S_{21}-C_{22}$ & 1.97913 & -0.64414 & $\sigma^{*} \mathrm{~N}_{18}-\mathrm{C}_{20}$ & 0.02884 & 0.51029 & 3.24 \\
\hline $\operatorname{LP}(1) \mathrm{N}_{18}$ & 1.62595 & -0.29005 & $\mathrm{LP}(1) \mathrm{C}_{20}$ & 0.89539 & -0.20912 & 226.28 \\
\hline $\operatorname{LP}(1) \mathrm{N}_{18}$ & 1.62595 & -0.29005 & $\sigma^{*} C_{4}-C_{5}$ & 0.03242 & 0.58195 & 4.66 \\
\hline $\operatorname{LP}(1) \mathrm{N}_{18}$ & 1.62595 & -0.29005 & $\sigma^{*} C_{5}-C_{6}$ & 0.03278 & 0.61608 & 5.06 \\
\hline$L P(1) S_{21}$ & 1.97659 & -0.67913 & $\sigma^{*} C_{20}-N_{25}$ & 0.02906 & 0.48456 & 4.67 \\
\hline $\mathrm{LP}(2) \mathrm{S}_{21}$ & 1.78956 & -0.29520 & $\mathrm{LP}(1) \mathrm{C}_{20}$ & 0.89539 & -0.20912 & 83.86 \\
\hline $\mathrm{LP}(1) \mathrm{N}_{25}$ & 1.62902 & -0.30652 & $\operatorname{LP}(1) C_{20}$ & 0.89539 & -0.20912 & 207.39 \\
\hline$\pi C_{4}-C_{5}$ & 0.37628 & 0.02535 & $\pi^{*} C_{1}-C_{6}$ & 0.31589 & 0.03637 & 265.10 \\
\hline $\mathrm{LP}(4) \mathrm{Cl}_{33}$ & 1.96307 & -0.23018 & $\sigma^{*} \mathrm{~N}_{18}-\mathrm{H}_{19}$ & 0.04012 & 0.78093 & 7.10 \\
\hline $\mathrm{LP}(1) \mathrm{O}_{34}$ & 1.99618 & -0.45926 & $\sigma^{*} \mathrm{~N}_{25}-\mathrm{H}_{26}$ & 0.02821 & 0.92279 & 25.02 \\
\hline
\end{tabular}

\subsection{Frontier molecular orbital analysis}

electrons, which refers to a negative potential. The region around $\mathrm{N}_{18}$ atom is more orange or yellow, which shows a less negative potential. The hydrogen atoms bear the maximum proportion of positive charge, whereas blue pale spread around Sulphur $S_{21}$ specifies less positive potential.
Molecular orbitals provide deep understanding of the nature of reactivity, conjugation and aromaticity of molecules [24]. According to frontier electron reactivity theory the chemical reaction occurs at a position, where the orbital overlap between HOMO and LUMO is maxima [25]. 


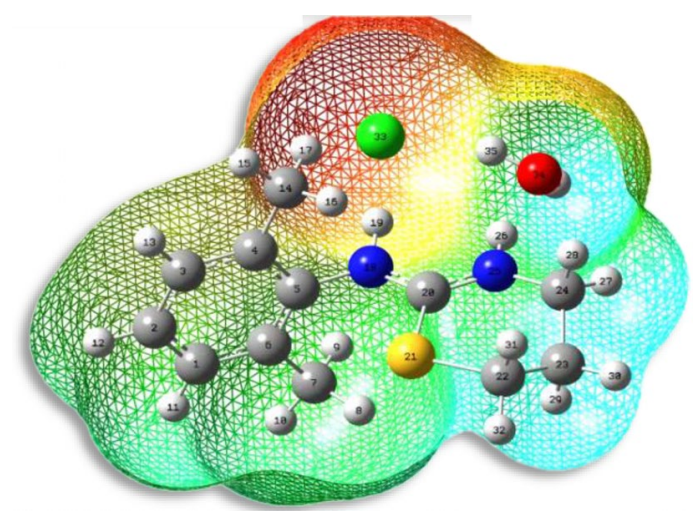

Fig. 2 Molecular electrostatic potential surface of Xylazine

The low Frontier orbital energy gap, $\mathrm{E}_{\mathrm{g}}(3.542 \mathrm{eV})$ makes Xylazine more reactive. This decrease in energy gap $\left(\mathrm{E}_{\mathrm{g}}\right)$ makes the electron excitation of the HOMO to be simple. The energy gap $\left(E_{g}\right)$ is a critical parameter in deciding the molecular electrical transport properties within the molecule, which determines the biological activity of the molecule [26]. The low value of $E_{\text {LUMO }}(-1.541 \mathrm{eV})$ reveals Xylazine as a soft electrophile [27]. The atomic orbital compositions of frontier molecular orbitals are shown in Fig. 3. It can be seen from the figure that, $\mathrm{HOMO}$ is found over the $\mathrm{Cl}$ atom and LUMO levels are spread over the molecule except the methyl groups.

\subsection{Chemical reactivity descriptors}

For comprehending the various aspects of pharmacological sciences several new chemical reactivity descriptors of the molecule have been put forward. DFT provides theoretical insight concerning qualitative chemical concepts like absolute electronegativity $(\chi)$, hardness $(\eta)$, softness

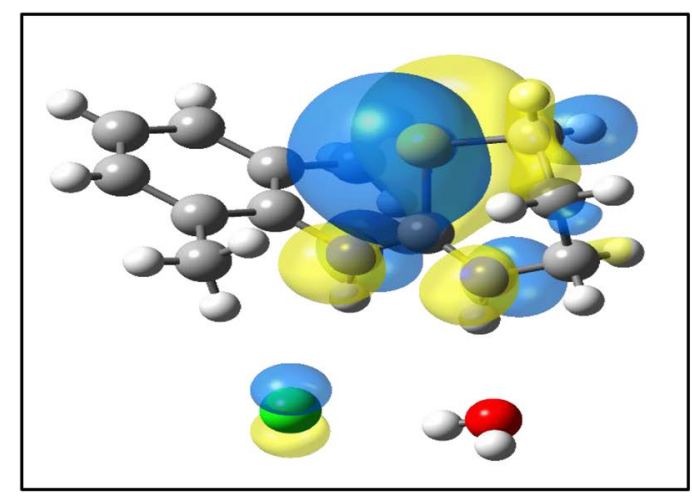

HOMO
$(S)$, electrophilicity index $(\omega)$, fractions of electrons transferred $(\Delta N)$, electron affinity $(A)$ and ionization potential (I) [28-35]. These aggregates have been calculated and are used to learn the chemical reactivity of molecular systems. The ionization potential and electron affinity are denoted with regard to $E_{\text {HOMO }}$ and $E_{L U M O}$ as

$I=-E_{\text {номо }}$

$A=-E_{L U M O}$

When the values of I and $A$ are known, the values of the absolute electron negativity $(\chi)$, absolute hardness ( $\eta$ ), chemical potential $(\mu)$ and softness can be calculated through the following equations.

$\eta=\frac{1}{2}\left(E_{\text {LUMO }}-E_{\text {HOMO }}\right)$

$\mu=-\frac{1}{2}\left(E_{\text {LUMO }}+E_{\text {HOMO }}\right)$

$S=\frac{1}{2 \eta}$

$\chi=-\frac{1}{2}\left(E_{\text {LUMO }}+E_{\text {HомО }}\right)$

The electrophilicity is a descriptor in characterizing the biological activities of molecules in the process of Quantitative Structure Activity Relationship (QSAR). Parr defined electrophilicity index $(\omega)$ as

$\omega=\frac{\mu^{2}}{2 \eta}$

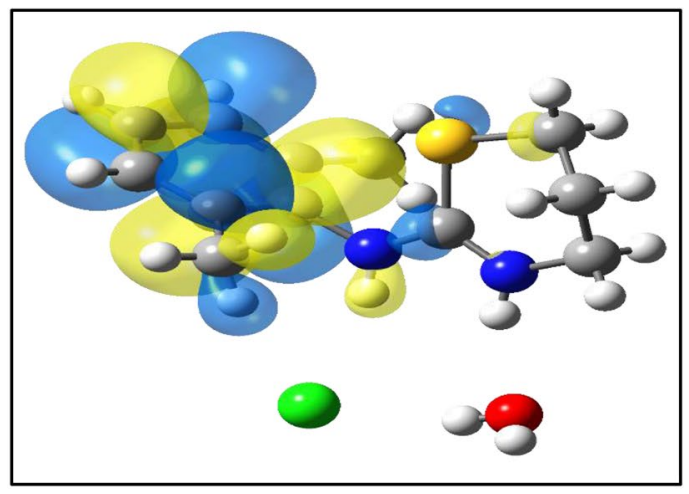

LUMO

Fig. 3 The atomic orbital compositions of frontier molecular orbitals 
The reactivity index which measures the stabilization energy when the system gains an additional electronic charge $\Delta N$ from the surrounding, is given by

$\Delta N_{\max }=-\frac{\mu}{\eta}$

The reactivity indices nucleofugality $\left(\Delta E_{n}\right)$ and electrofugality $\left(\Delta E_{e}\right)$ are detailed as

$\Delta E_{n}=-A+\omega=\frac{(\mu+\eta)^{2}}{2 \eta}$

$\Delta E_{e}=I+\omega=\frac{(\mu-\eta)^{2}}{2 \eta}$

The global descriptors are given in Table 3. The low ionization energy $(5.083 \mathrm{eV})$ indicates that the molecule is less stable [36]. The negative chemical potential $(-3.312 \mathrm{eV})$

Table 3 HOMO-LUMO energy and related molecular parameters

\begin{tabular}{lr}
\hline Parameter & \multicolumn{1}{c}{$\mathrm{eV}$} \\
\hline E $_{\text {HOMO }}$ & -5.083 \\
$\mathrm{E}_{\text {LUMO }}$ & -1.541 \\
$E \mathrm{~g}$ & 3.542 \\
HARDNESS $(\eta)$ & 1.771 \\
POTENTIAL $(\mu)$ & -3.312 \\
SOFTNESS $(\mathrm{S})$ & 1.436 \\
ELECTRONEGATIVITY $(x)$ & 3.312 \\
ELECTROPHILICITY INDEX $(\omega)$ & 3.096 \\
ADD.ELECTRONIC CHARGE $\left(\Delta \mathrm{N}_{\max }\right)$ & 1.870 \\
NUCLEOFUGALITY $\left(\Delta \mathrm{E}_{\mathrm{n}}\right)$ & 1.555 \\
ELECTROFUGALITY $\left(\Delta \mathrm{E}_{\mathrm{e}}\right)$ & 8.179 \\
\hline
\end{tabular}

shows that it does not crumble spontaneously into elements. It is obvious that, the chemical hardness withstands the deformation or polarization of the electron cloud of the atoms, ions or molecules under small disturbance of chemical reaction. A hard molecule has a large energy gap and a soft molecule has a small energy gap. In this study, the molecule with low hardness value $(1.771 \mathrm{eV})$ shows that it is a soft molecule, which is justified from the low $\mathrm{E}_{\mathrm{g}}$. The high value of electrophilicity index $(3.096 \mathrm{eV})$ supports its electrophilic behaviour.

\subsection{Vibrational analysis}

The recorded FTIR and FT-Raman spectra of the title molecule in comparison with the simulated spectra are shown in Figs. 4 and 5 respectively. Internal valence coordinates are defined and given in Table S1 (Supplementary material). Hand-picked spectral assignments along with the calculated FTIR and FT-Raman intensities pertinent to this study are given in Table 4.

The $\mathrm{C}-\mathrm{H}$ ring stretching vibration generally occurs in the region $3100-3000 \mathrm{~cm}^{-1}$. It is observed at $3045 \mathrm{~cm}^{-1}$ in FTIR spectrum and FT-Raman spectrum in the title molecule. This mode is found to be weak due to the charge transfer between hydrogen and carbon atoms [21]. The in-plane aromatic $\mathrm{C}-\mathrm{H}$ stretching band is observed at $1166 \mathrm{~cm}^{-1}$ in FT-IR spectrum and $1163 \mathrm{~cm}^{-1}$ in FT-Raman spectrum. The out-of-plane bending vibration appear in the range $1000-750 \mathrm{~cm}^{-1}$ [37], which is observed at $860 \mathrm{~cm}^{-1}$ in FTIR spectrum and at $870 \mathrm{~cm}^{-1}$ in FT-Raman spectrum.

The phenyl ring $\mathrm{C}-\mathrm{C}$ stretching vibrations occur with variable intensities. These bands are observed at 1587 and $1258 \mathrm{~cm}^{-1}$ in FTIR spectrum and at 1591 and $1260 \mathrm{~cm}^{-1}$ in FT-Raman spectrum. The bands at 708 and $679 \mathrm{~cm}^{-1}$ in

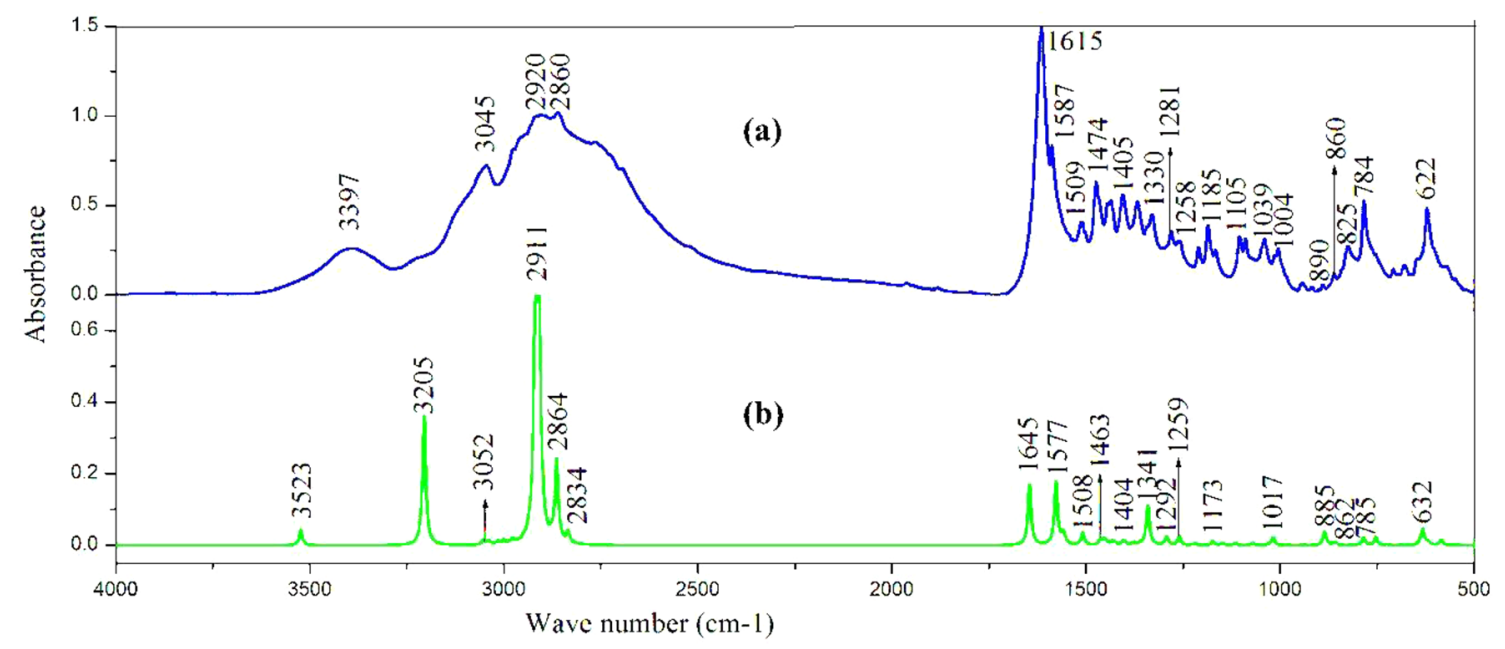

Fig. 4 Comparison of $\mathbf{a}$ experimental and $\mathbf{b}$ simulated FTIR spectra of Xylazine 


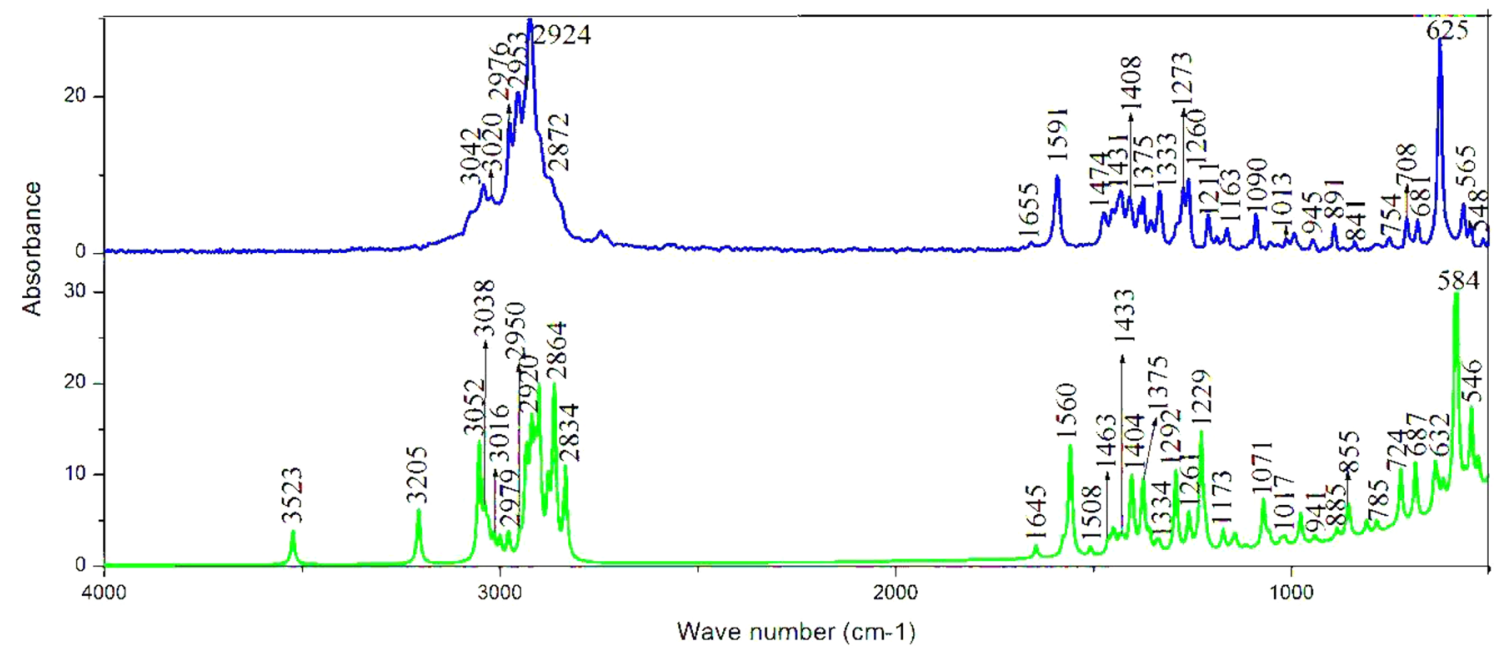

Fig. 5 Comparison of $\mathbf{a}$ experimental and $\mathbf{b}$ simulated FT-Raman spectra of Xylazine

Table 4 Selected vibrational assignments by normal coordinate analysis based on SQM force field calculations

\begin{tabular}{|c|c|c|c|c|c|}
\hline \multicolumn{3}{|c|}{ Calculated (DFT) } & \multicolumn{2}{|c|}{ Observed $\left(\mathrm{cm}^{-1}\right)$} & \multirow[t]{2}{*}{ Assignment } \\
\hline Scaled $\left(\mathrm{cm}^{-1}\right)$ & $I_{\mathbb{R}}$ & $I_{\mathrm{Ra}}$ & FTIR & FT-Raman & \\
\hline 3523 & 68.64 & 3.86 & 3397 & - & $\mathrm{UOH}(100)$ \\
\hline 3205 & 570.46 & 6.22 & 3217 & - & UNH (99) \\
\hline 3052 & 19.58 & 13.7 & 3045 & 3045 & $\mathrm{U}_{\mathrm{Ph}} \mathrm{CH}(99)$ \\
\hline 3000 & 15.47 & 3.45 & 3005 & 3005 & $u C H_{2 i p}(82), \cup \mathrm{CH}_{3 \mathrm{op}}(16)$ \\
\hline 2978 & 19.52 & 3.88 & 2971 & 2976 & $u \mathrm{CH}_{3 \mathrm{ip}}(76), \cup \mathrm{CH}_{3 \mathrm{op}}(21)$ \\
\hline 2930 & 6.72 & 12.5 & 2920 & 2924 & $\mathrm{uCH}_{2 \mathrm{ss}}(95)$ \\
\hline 2879 & 17.23 & 10.3 & 2860 & 2872 & $\mathrm{UCH}_{3 s \mathrm{~s}}(95)$ \\
\hline 1645 & 268.42 & 2.29 & 1615 & 1628 & $\beta \mathrm{NH}(53), \beta \mathrm{NHCl}(29)$ \\
\hline 1577 & 276.92 & 3.37 & 1587 & 1591 & $\mathrm{U}_{\mathrm{Ph}} \mathrm{CC}(62), \beta C H(11)$ \\
\hline 1508 & 53.62 & 2.15 & 1509 & - & $\mathrm{BH}_{2} \mathrm{O}(86)$ \\
\hline 1448 & 6.43 & 4.12 & 1444 & 1452 & $\beta \mathrm{CH}_{3 \mathrm{op}}(58), \mathrm{U}_{\mathrm{Ph}} \mathrm{CC}$ (13), $\beta_{\mathrm{Ph}} \mathrm{CH}$ (10) \\
\hline 1379 & 3.82 & 7.65 & - & 1375 & $\mathrm{CH}_{2 w g}(49)$ \\
\hline 1375 & 7.65 & 9.59 & 1368 & 1354 & $\beta C \mathrm{H}_{3 \mathrm{ip}}(62), \mathrm{U}_{\mathrm{Ph}} \mathrm{CC}(11)$ \\
\hline 1292 & 37.03 & 10.5 & 1281 & 1273 & $\mathrm{CH}_{2} \mathrm{wg}(34), \mathrm{uCN}(15)$ \\
\hline 1261 & 8.51 & 5.63 & 1258 & 1260 & $\mathrm{U}_{\mathrm{Ph}} \mathrm{CC}(78)$ \\
\hline 1149 & 7.57 & 3.14 & 1166 & 1163 & $\beta_{\mathrm{Ph}} \mathrm{CH}(73), \mathrm{U}_{\mathrm{Ph}} \mathrm{CC}(22)$ \\
\hline 1020 & 3.09 & 3.35 & 1004 & 1013 & $\mathrm{CH}_{3 \text { roc }}(51)$ \\
\hline 862 & 9.27 & 5.38 & 860 & 870 & $\mathrm{CH}_{2 \text { roc }}(37), \mathrm{U}_{\mathrm{R} 2} \mathrm{CC}$ (13) \\
\hline 724 & 3.49 & 10.7 & 708 & 708 & $\mathrm{Ph}_{\text {puck }}(19), \mathrm{u}_{\mathrm{Ph}} \mathrm{CC}(12), \mathrm{v}_{\mathrm{Me}} \mathrm{CC}(11)$ \\
\hline 687 & 1.12 & 11.4 & 679 & 681 & $\mathrm{Ph}_{\text {puck }}(39), \mathrm{gCN}(27), \mathrm{g}_{\mathrm{Me}} \mathrm{CC}(12)$ \\
\hline 584 & 24.02 & 42.1 & 570 & 565 & UCS (54) \\
\hline 465 & 0.20 & 11.7 & - & 442 & $\beta_{\mathrm{Me}} \mathrm{CC}(36), \beta C N(20)$ \\
\hline
\end{tabular}

FTIR spectrum and 708 and $681 \mathrm{~cm}^{-1}$ in FT-Raman spectrum are assigned to the $\mathrm{C}-\mathrm{C}-\mathrm{C}$ in-plane bending modes.

Identifying the assignments of $\mathrm{C}-\mathrm{N}$ stretching wavenumber from other vibrations is found to be a difficult task. The $\mathrm{C}-\mathrm{N}$ stretching vibrations are active in the range $1220-1330 \mathrm{~cm}^{-1}$. The band observed at $1281 \mathrm{~cm}^{-1}$ in the FTIR spectrum and $1273 \mathrm{~cm}^{-1}$ in the FT-Raman spectra are assigned to $\mathrm{C}-\mathrm{N}$ stretching vibrations. The $\mathrm{C}-\mathrm{N}$ inplane bending vibration usually occurs at $448 \mathrm{~cm}^{-1}$. In this sample, it is found as a weak band at $442 \mathrm{~cm}^{-1}$ in FT-Raman spectrum with no corresponding FTIR band. The molecule possesses two methyl groups directly connected with the benzene ring. For the methyl substituted benzene derivative, the $\mathrm{C}-\mathrm{H}$ stretching mode 
normally occurs at lower wavenumbers than those of the aromatic ring. The methyl asymmetric $\mathrm{C}-\mathrm{H}$ stretching is observed at $2971 \mathrm{~cm}^{-1}$ in FTIR spectrum and $2976 \mathrm{~cm}^{-1}$ in FT-Raman spectrum. $\mathrm{CH}_{3}$ symmetric stretching mode is observed at $2860 \mathrm{~cm}^{-1}$ in FTIR spectrum and 2872 in FT-Raman spectrum. The deformation and rocking vibrations of methyl group normally appears in the region $1465-1440,1390-1370$ and $1040-990 \mathrm{~cm}^{-1}$ respectively [38]. The band at $1444 \mathrm{~cm}^{-1}$ in FTIR spectrum and $1452 \mathrm{~cm}^{-1}$ in FT-Raman spectrum are assigned to $\mathrm{CH}_{3}$ asymmetric bending vibration. The symmetric deformation vibration is observed at $1368 \mathrm{~cm}^{-1}$ in FTIR spectrum and $1354 \mathrm{~cm}^{-1}$ in FT-Raman spectrum. The band at $1004 \mathrm{~cm}^{-1}$ in FTIR spectrum and at $1013 \mathrm{~cm}^{-1}$ in FTRaman spectrum is assigned to $\mathrm{CH}_{3}$ rocking mode. In methylene, the asymmetric stretching vibration is found at $3005 \mathrm{~cm}^{-1}$ in FTIR and FT-Raman spectra. The symmetric stretching mode is observed at 2920 and $2924 \mathrm{~cm}^{-1}$ in FTIR and FT-Raman spectra. The methylene wagging vibrations is found at $1375 \mathrm{~cm}^{-1}$ in FT-Raman spectrum.

The bond lengths of hydrogen bonds $\mathrm{H}_{19} \cdots \mathrm{Cl}_{33}$ (2.104 $\AA$ ) , $\mathrm{H}_{26} \cdots \mathrm{Cl}_{33}\left(2.104 \AA\right.$ ) and $\mathrm{O}_{34} \cdots \mathrm{H}_{35}(2.232 \AA)$ will reveal the strength of the bonds. Since the bond lengths of Xylazine molecule are below $2.5 \AA$, the hydrogen bonds are found to be very strong. The hydrogen bonding brings notable downward shift in wavenumbers. These hydrogen bonds influence the various $\mathrm{NH}$ and $\mathrm{OH}$ vibrational modes. The stretching modes are the most sensitive bands of hydrogen bonding. The position and the lowering of $\mathrm{NH}$ stretching frequency $\left(\sim 100 \mathrm{~cm}^{-1}\right)$ indicate the disclosure of strong $\mathrm{N}-\mathrm{H} \cdots \mathrm{Cl}$ hydrogen bonding. Another hydrogen bonding $\mathrm{O}-\mathrm{H} \cdots \mathrm{O}$ is reflected in the FTIR spectrum by the lowering of $\mathrm{O}-\mathrm{H}$ stretching frequency from the expected value of $150 \mathrm{~cm}^{-1}$.

\subsection{Structure-activity relationship analysis}

Quantitative Structure-Activity Relationship (QSAR) plays a prominent role in modern chemistry and biochemistry. It is used for its quantitative affinity and physicochemical aspects of drug like molecules and ligands [39]. QSAR correlates structural, chemical, statistical and physical properties with its biological activities. In order to access the drug-likeness of a molecule the Lipinski's Rule of Five also known as the Pfizer's rule of five is used, which give a detailed account of balance between the molecular properties that influences its pharmacodynamics, pharmacokinetics and ADME (absorption, distribution, metabolism and excretion) [40].

Xylazine is highly lipophilic in nature as a consequence, it directly stimulates the central adrenergic receptors as well as peripheral adrenoceptors in a variety of tissues
[41]. As an agonist, it decreases the neurotransmission of norepinephrine.

and dopamine in the central nervous system [42]. It does so by mimicking norepinephrine in binding to presynaptic surface auto receptors, which leads to feedback inhibition of norepinephrine [43]. Xylazine is examined thoroughly in pubchem database in order to find its structural analogues. There are 420 structural analogous and among them 383 fulfilled Lipinski's rule of 5 [39]. In which 25 homologous are tested for bioassays. Bioassays are conducted to measure the potency of the substance on living organisms, which are indispensable in the development of new drugs. Multiple Linear Regression (MLR) is used as a chemo-metric method for the variable selection and statistical fitting of molecules to understand their chemical information. MLR draw a group of random variables and make an attempt to find a mathematical association among them. The drug-likeness properties are tabulated in Supplementary Material Table S2. Molecular weight, hydrogen acceptor, hydrogen donor and Log P of the observed 25 molecules are taken as independent variables and docking score as dependent variable for MLR. Open office is used for MLR calculation. The MLR result shows that $R$ value is 0.901 and $R 2$ is 0.812 . These values of $R$ and $R 2$ are proximate to +1 , and so it indicates the existence of positive and good correlation between drug likeness and docking score [44]. $81.2 \%$ of the change can be explained by the change in the 4 independent variables. It is found that the docking score keeps on changing along with drug-likeness properties; as a consequence, there is a relationship between the structure analogue of Xylazine's structural properties and their activity.

\subsection{Molecular docking}

Molecular docking analysis is carried out to perceive the desirable inhibitor for adrenergic receptor. Molecular docking simulations are performed on Auto Dock Vina software. The 3D crystal structure of bovine (Bos taurus) adrenergic receptor is acquired from Protein Data Bank (PDB ID: 3PVW). Auto Dock Tools (ADT) graphical user interface is used to reckon Kollman charges and to add polar hydrogen. Active site of the protein is defined in a manner that it incorporated residues of the active site within the grid dimensions of $30 \times 30 \times 30 \AA$. The popular algorithm, Lamarckian Genetic Algorithm (LGA) in Auto dock Vina is used for docking. The ligand (Xylazine's structural analogue), which binds to the receptor (adrenergic receptor) by hydrophobic interactions is $\mathrm{N}$-(2, 6-dimethylphenyl)-4, 4-dimethyl-5-methylidene-1, 3-thiazol-2-amine (pubchem id: CID 731,997) or N97, which is displayed in 


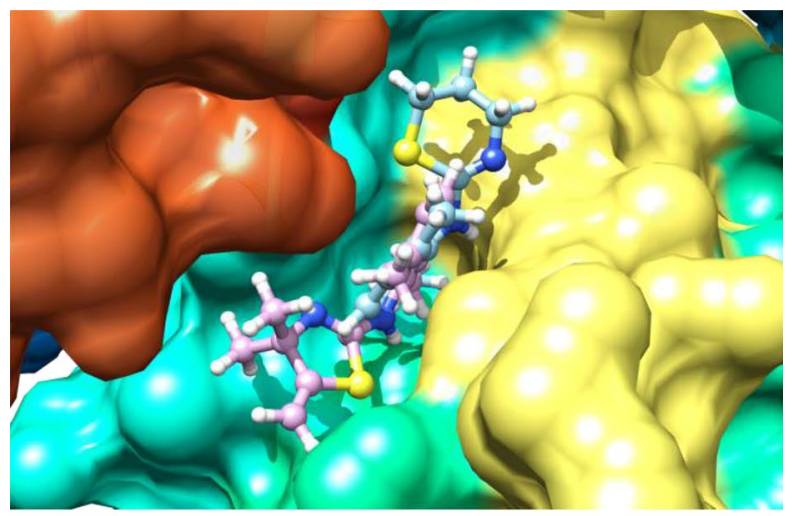

(a)

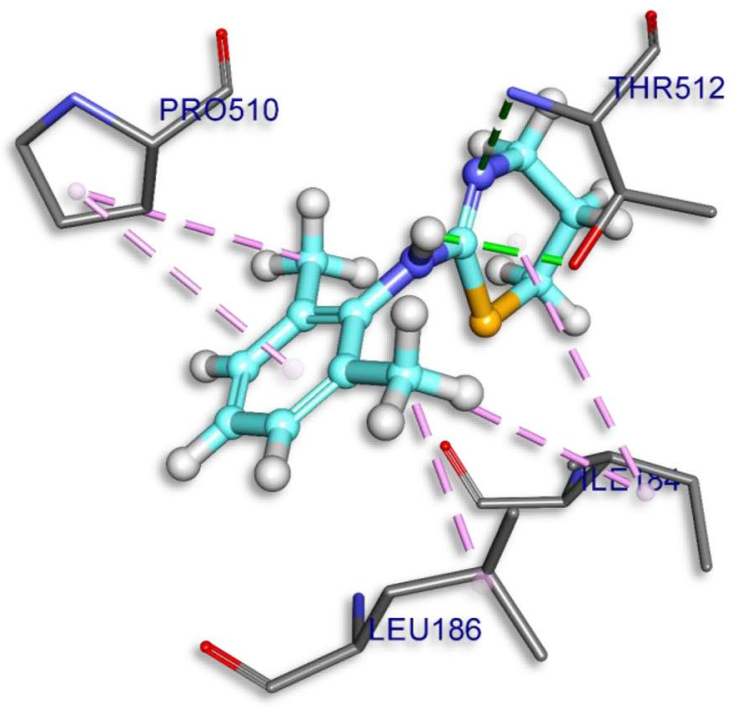

(b)

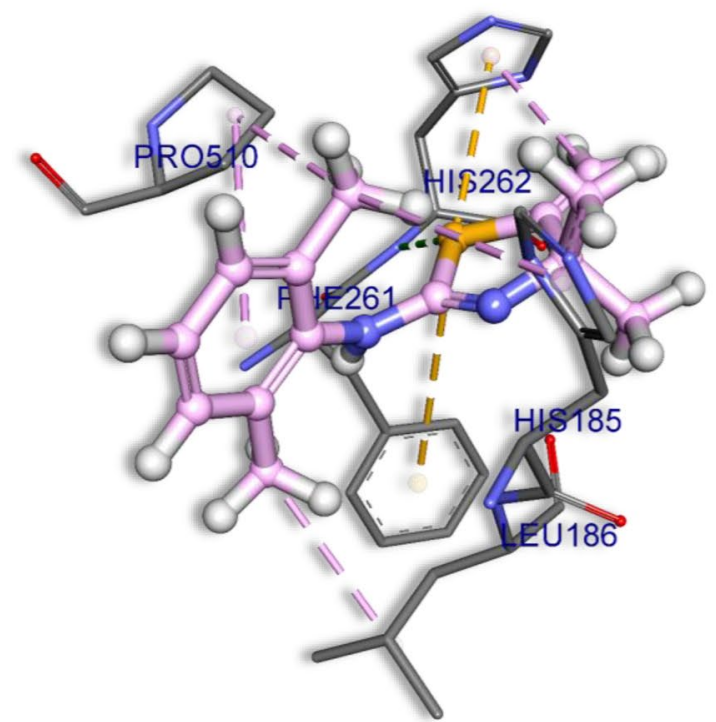

(c)
४ Fig.6 a Comprehensive perception of Xylazine, N97 and adrenergic receptor after docking. (a) Secondary structure adrenergic receptor represented by surface model and Xylazine (blue) and N97 (pink) are represented is by ball stick model and were coloured according to elements, $\mathbf{b}$ Interactions of Xylazine (blue) with adrenergic receptor amino acids (grey). Bonds are in dots. Xylazine surrounding amino acids are in three letters code represented in blue, $\mathbf{c}$ Interactions of N97 (pink) with adrenergic receptor amino acids (grey). Bonds are in dots. N97 surrounding amino acids are in three letters code represented in blue

Fig. 6. As it is clearly seen from Table 5, 6 and Fig. 6 the surrounding amino acids are Valine (VAL 205, 255), Leucine (LEU 271,324), isoleucine (ILE 197), and alanine (ALA 218). Xylazine's structural analogue, $\mathrm{N} 97$ forms a stable complex with bovine adrenergic receptor which is evident from its binding affinity $(-7.3 \mathrm{kcal} / \mathrm{mol})$ compared to Xylazine $(-5.7 \mathrm{kcal} / \mathrm{mol})$. 
Table 5 Interaction analysis of docking Xylazine (XY)

\begin{tabular}{llll}
\hline Bond name & Distance $(\AA)$ & Bond category & Bond type \\
\hline P:XY:H7-A:THR512:OG1 & 2.48608 & Hydrogen Bond & Conventional Hydrogen Bond \\
A:THR512:N-P:XY:N2 & 3.02803 & Hydrogen Bond & Conventional Hydrogen Bond \\
P:XY:C11-A:LEU186 & 3.71898 & Hydrophobic & Alkyl \\
P:XY-A:PRO510 & 4.72677 & Hydrophobic & Pi-Alkyl \\
P:XY:C10-A:PRO510 & 4.80835 & Hydrophobic & Alkyl \\
P:XY:C11-A:ILE184 & 5.43238 & Hydrophobic & Alkyl \\
A:ILE184-P:XY & 5.49055 & Hydrophobic & Alkyl \\
\hline
\end{tabular}

Table 6 Interaction analysis of docking N97

\begin{tabular}{|c|c|c|c|}
\hline Bond name & Distance $(\AA ̊)$ & Bond category & Bond type \\
\hline $\begin{array}{c}\text { A:HIS262:N- } \\
\text { P:N97:S1 }\end{array}$ & 3.35257 & Hydrogen Bond & $\begin{array}{l}\text { Conventional } \\
\text { Hydrogen } \\
\text { Bond }\end{array}$ \\
\hline A:HIS262-P:N97:C9 & 3.65338 & Hydrophobic & Pi-Alkyl \\
\hline $\begin{array}{r}\text { P:N97:C12- } \\
\text { A:LEU186 }\end{array}$ & 3.77187 & Hydrophobic & Alkyl \\
\hline $\begin{array}{r}\text { P:N97:C13- } \\
\text { A:PRO510 }\end{array}$ & 4.05654 & Hydrophobic & Alkyl \\
\hline P:N97:S1-A:HIS262 & 4.21349 & Other & Pi-Sulfur \\
\hline A:HIS185-P:N97:C3 & 4.24948 & Hydrophobic & Pi-Alkyl \\
\hline $\begin{array}{l}\text { A:HIS185- } \\
\text { P:N97:C13 }\end{array}$ & 5.20691 & Hydrophobic & Pi-Alkyl \\
\hline P:N97-A:PRO510 & 5.21065 & Hydrophobic & Pi-Alkyl \\
\hline A:HIS262-P:N97 & 5.2516 & Hydrophobic & Pi-Alkyl \\
\hline $\begin{array}{l}\text { P:N97:S1- } \\
\text { A:PHE261 }\end{array}$ & 5.57002 & Other & Pi-Sulfur \\
\hline
\end{tabular}

\subsection{Conclusion}

The investigation of the present work illuminates the molecular properties of Xylazine. The shortening of $\mathrm{C}-\mathrm{N}$ bond length shows the effect of resonance in that part of the molecule. The stability of the molecule is further improved by $\mathrm{N}_{18}-\mathrm{H}_{19} \cdots \mathrm{Cl}_{33}, \mathrm{~N}_{25}-\mathrm{H}_{26} \cdots \mathrm{O}_{34}$ and $\mathrm{O}_{34}-\mathrm{H}_{35} \cdots$ $\mathrm{Cl}_{33}$ interactions that are well defined using the NBO and vibrational analysis. The small energy gap (Eg) discloses effective charge transfer and this leads to the enhanced stability of the molecule. The most potent adrenergic receptor inhibitor is found by scanning through the chemical databases of Xylazine analogues. Docking tool is used to predict relative orientation and interaction position in domains of adrenergic receptor which gave an accurate and deep understanding of potency and molecular interaction of Xylazine analogue.

Acknowledgements The author thanks the University Grants Commission (UGC), India, for the allocation of a Teacher Fellowship under FDP scheme leading to Ph.D. The author also thanks SAIF, Chennai for the support in recording the FT-IR and FT-Raman spectra.
Funding There is no research funding for the present work.

Code availability No code has been used in the present work.

\section{Compliance with ethical standard}

Conflicts of interest The authors declare that they have no conflict of interest.

Availability of data and material Data may be available from the author after the publication of the article.

Ethics approval Not applicable.

Consent to participate Not applicable.

Consent for publication Author is giving his consent for publication of the article in your reputed journal as a regular article (i.e., without paying article publication charges).

\section{References}

1. Clarke K, Hall L (1969) "Xylazine"-a new sedative for horses and cattle. Vet Rec 85:512-517

2. Krukle-BerziÃa K, ActiÃš A (2014) Investigation of the phase transitions occurring during and after the dehydration of xylazine hydrochloride monohydrate. Int J Pharm 469:40-49

3. Yaksh TL (1985) Pharmacology of spinal adrenergic systems which modulate spinal nociceptive processing. Pharmacol Biochem Behav 22:845-858

4. Fleetwood-Walker SM, Mitchell R, Hope PJ, Molony V, Iggo A (1985) An alpha-2 receptor mediates the selective inhibition by noradrenaline of nociceptive responses of identified dorsal horn neurons. Brain Res 334:243-254

5. Hsu WH (1981) Xylazine-induced depression and its antagonism by a adrenergic blocking agents. J Pharmacol Exp Ther 218:188-192

6. Hall LW, Clarke KW, Trim CM (2001) Veterinary Anaesthesia, 7th edn. Harcourt Publisher Ltd., England

7. Kurban H, Dalkilic M, Temiz S, Kurban M (2020) Tailoring the structural properties and electronic structure of anatase, brookite and rutile phase $\mathrm{TiO}_{2}$ nanoparticles: DFTB calculations. Comput Mater Sci 183:109843

8. MJ Frisch, GW Trucks, HB Schlegel, GE Scuseria, MA Robb, JR Cheeseman, G Scalmani, V Barone, B Mennucci, GA Petersson, H Nakatsuji, M Caricato, X Li, HP Hratchian, AF Izmaylov, J Bloino, G Zheng, JL Sonnenberg, M Hada, M Ehara, K Toyota, R Fukuda, J Hasegawa, M Ishida, T Nakajima, Y Honda, O Kitao, H Nakai, T 
Vreven, JA Montgomery, Jr., JE Peralta, F Ogliaro, M Bearpark, JJ Heyd, E Brothers, KN Kudin, VN Staroverov, T Keith, R Kobayashi, J Normand, K Raghavachari, A Rendell, JC Burant, SS lyengar, J Tomasi, M Cossi, N Rega, JM Millam, M Klene, JE Knox, JB Cross, V Bakken, C Adamo, J Jaramillo, R Gomperts, RE Stratmann, O Yazyev, AJ Austin, R Cammi, C Pomelli, JW Ochterski, RL Martin, K Morokuma, VG Zakrzewski, GA Voth, P Salvador, JJ Dannenberg, S Dapprich, AD Daniels, O Farkas, JB Foresman, JV Ortiz, J Cioslowski, DJ Fox, (2010) Gaussian 09, revision B.01, Gaussian, Inc., Wallingford, CT.

9. Becke AD (1997) Density-functional thermochemistry. V. Systematic optimization of exchange-correlation functionals. J Chem Phys 107:8554-8580

10. Stephens PJ, Devlin FJ, Chabalowski CF, Frisch M (1994) Ab Initio calculation of vibrational absorption and circular dichroism spectra using density functional force fields. J Phys Chem 98:11623-11627

11. ED Glendening, AE Reed, JE Carpenter, F Weinhold (1998) NBO Version 3.1, TCl. University of Wisconsin, Madison.

12. Sundius T (1990) Molvib-A flexible program for force field calculations. J Mol Struct 218:321-326

13. Sundius $T$ (2002) Scaling of ab initio force fields by MOLVIB. Vib Spectrosc 29:89-95

14. Trott O, Olson AJ (2010) AutoDock Vina: improving the speed and accuracy of docking with a new scoring function, efficient optimization and multithreading. J Comput Chem 31:455-461

15. Morris GM, Goodsell DS, Halliday RS, Huey R, Hart WE, Belew RK, Olson AJ (1998) Automated docking using a Lamarckian genetic algorithm and an empirical binding free energy function. J Comput Chem 19:1639-1662

16. Veidis MV, Orola L, Arajs R (2008) N-(2,6-Dimethylanilino)-5,6-dihydro-4H-1,3-thiazin-3-ium chloride monohydrate. Acta Cryst E64:1062

17. Vallejos ST, Erben MF, Piro OE, Castellano EE (2009) C.O. Della Vedova, $\mathrm{N}-\mathrm{H} \cdots \mathrm{S}=\mathrm{C}$ hydrogen bond in O-alkyl N-methoxycarbonyl thiocarbamates, $\mathrm{ROC}(\mathrm{S}) \mathrm{N}(\mathrm{H}) \mathrm{C}(\mathrm{O}) \mathrm{OCH} 3(\mathrm{R}=\mathrm{CH} 3-$ $\mathrm{CH} 3 \mathrm{CH} 2-)$. Polyhedron 28:937-946

18. James C, AmalRaj A, Reghunathan R, Jayakumar VS, Hubert Joe I (2006) Structural conformation and vibrational spectroscopic studies of 2,6-bis(p-N, N-dimethyl benzylidene) cyclohexanone using density functional theory. J Raman Spectrosc 37:1381-1392

19. Ravikumar C, Hubert Joe I, Sajan D (2010) Vibrational contributions to the second-order nonlinear optical properties of $\pi$-conjugated structure acetoacetanilide. Chem Phys 369:1-7

20. Ravikumar C, Hubert Joe I, Jayakumar VS (2008) Charge transfer interactions and nonlinear optical properties of push-pull chromophore benzaldehyde phenylhydrazone: A vibrational approach. Chem Phys Lett. 460:552-558

21. Ravikumar C, Hubert Joe I (2010) Electronic absorption and vibrational spectra and nonlinear optical properties of 4-methoxy-2-nitroanilinePhys. Chem Chem Phys 12:9452-9460

22. Luque FJ, Orozco M, Bhadane PK, Gadre SR (1993) SCRF calculation of the effect of water on the topology of the molecular electrostatic potential. J Phys Chem 97:9380-9384

23. Murray JS, Sen K (1996) Molecular Electrostatic Potentials: Concepts and Applications, 1st edn. Elsevier, Amsterdam

24. Keresztury G, Holly S, Besenyei G, Varga J, Wang A, Durig JR (1993) Vibrational spectra of monothiocarbamates-II. IR and Raman spectra, vibrational assignment, conformational analysis and ab initio calculations of S-methyl- $\mathrm{N}, \mathrm{N}$ dimethylthiocarbamate. Spectrochim Acta part A: Mol Spectrosc 49A:2007-2017
25. Fukui K (1975) Theory of Orientation and Stereo Selection, 1st edn. Springer-Verlag, Berlin Heidelberg, New York

26. Corredor C, Teslova T, Canamares MV, Chen Z, Zhang J, Lombardi JR, Leona M (2009) Raman and surface-enhanced Raman spectra of chrysin, apigenin and luteolin. Vibr Spectrosc 49:190-195

27. Silverstein RM, Bassler GC, Morrill TC (1991) Spectrometric Identification of Organic Compounds, 5th edn. Wiley, New York

28. Parr RG, Donnelly RA, Levy M, Palke WE (1978) Electronegativitythe density functional view Point. J Chem Phys 68:3801-3807

29. Parr RG, Pearson RG (1983) Absolute hardness: comparison parameter to absolute electronegativity. J Am Chem Soc 105:7512-7516

30. Koopmans $T$ (1993) Ordering of wave functions and eigen energies to the individual electrons of an atom. Physica 1:104-113

31. Pearson RG (1963) Hard and soft acids and bases. J Am Chem Soc 85:3533-3539

32. Lesar A, Milosev I (2009) Density functional study of the corrosion inhabitation properties of 1, 2, 4- triazole and its amino derivatives. Chem Phys Lett 483:198-203

33. Parr RG, Szentpaly L, Liu S (1999) Electrophilicity index. J Am Chem Soc 121:1922-1924

34. Ayers PW, Anderson JSM, Bartolotti LJ (2005) Perturbative perspectives on the chemical reaction prediction Problem. Int J Quantum Chem 101:520-534

35. Roo G, Loverix S, Brosens E, Van Belle K, Wyns L, Geerlings $P$, Messens J (2006) The activation of electrophile, nucleophile and leaving group during the reaction catalysis by P1258 arsenate reductase. Chem Bio Chem 7:981-989

36. Chakraborty T, Ghosh DC (2010) Computation on the atomic radii through the conjoint action of the effective nuclear change and the ionization energy. Mol Phys 108:2081-2092

37. Varsanyi G (1969) Vibrational Spectra of Benzene Derivatives. Academic Press, NewYork

38. Reddy BV, Rao GR (1994) Transferable valence force fields for substituted benzenes: part I. Monohalogenated anisoles. Vib Spectrosc 6:231-250

39. Nantasenamat C, Isarankura-Na-Ayudhya C, Prachayasittikul $V$ (2010) Advances in computational methods to predict the biological activity of compounds. Expert Opin Drug Discov 5:633-654

40. Lipinski CA, Lombardo F, Dominy BW, Feeney PJ (2001) Experimental and computational approaches to estimate solubility and permeability in drug discovery and development settings. Adv Drug Deliv Rev 46:3-26

41. Greene SA, Thurmon JC (1988) Xylazine-a review of its pharmacology and use in veterinary medicine. J Vet Pharmacol Ther 11:295-313

42. Ruiz-Colón K, Chavez-Arias C, Díaz-Alcalá JE, Martínez MA (2014) Xylazine intoxication in humans and its importance as an emerging adulterant in abused drugs: a comprehensive review of the literature. Forensic Sci Int 240:1-8

43. Park JW, Chung HW, Lee EJ, Jung KH, Paik JY, Lee KH (2013) a2-Adrenergic agonists including Xylazine and dexmedetomidine inhibit norepinephrine transporter function in SK-N-SH cells. Neurosci Lett 541:184-189

44. Creswell JW (2002) Research Design: Qualitative, Quantitative, and Mixed Methods Approaches, 2nd edn. SAGE Publications, California

Publisher's Note Springer Nature remains neutral with regard to jurisdictional claims in published maps and institutional affiliations. 